\title{
Setting Road Safety Targets in Cambodia: A Methodological Demonstration Using the Latent Risk Time Series Model
}

\author{
Jacques J. F. Commandeur, ${ }^{1,2}$ Paul Wesemann, ${ }^{3}$ Frits Bijleveld, \\ Voun Chhoun, ${ }^{4}$ and Socheata Sann ${ }^{5}$ \\ ${ }^{1}$ VU University, Amsterdam, Netherlands \\ ${ }^{2}$ SWOV Institute for Road Safety Research, The Hague, Netherlands \\ ${ }^{3}$ Foundation Road Safety for All, Voorburg, Netherlands \\ ${ }^{4}$ Ministry of Public Works and Transport, General Department of Transport, Phnom Penh, Cambodia \\ ${ }^{5}$ Handicap International, Phnom Penh, Cambodia
}

Correspondence should be addressed to Jacques J. F. Commandeur; j.j.f.commandeur@vu.nl

Received 11 July 2016; Accepted 4 September 2016; Published 9 January 2017

Academic Editor: Sze Chun Wong

Copyright (C) 2017 Jacques J. F. Commandeur et al. This is an open access article distributed under the Creative Commons Attribution License, which permits unrestricted use, distribution, and reproduction in any medium, provided the original work is properly cited.

\begin{abstract}
We present the methodology used for estimating forecasts for the number of road traffic fatalities in 2011-2020 in Cambodia based on observed developments in Cambodian road traffic fatalities and motor vehicle ownership in the years 1995-2009. Using the latent risk time series model baseline forecasts for the fatality risk were estimated for the years 2010-2020. These baseline forecasts were then used to obtain estimates for the future number of fatalities based on three scenarios for the future Cambodian growth in motor vehicle ownership: a low, a middle, and a high growth scenario. The middle growth scenario results in an expected death toll of approximately 3,200 in 2020. In 2010, it was therefore decided in Cambodia to set the target at a 50\% reduction of this number or 1,600 fatalities in 2020. If it is possible to achieve this target by taking additional actions to improve road safety, then a total of 7,350 lives could be saved in Cambodia over the whole 2011-2020 period.
\end{abstract}

\section{Introduction}

Road crashes and their consequences are a growing worldwide problem. This has been well documented in a number of WHO reports. The Global Status Report on road safety [1] states that in 20101.24 million deaths were on world's roads. Death rates (road traffic deaths per 100,000 population) in middle- and low-income countries are twice (or more) the rate in high-income countries. The death rates per registered motorized vehicles differ even more. Projections in previous WHO reports [2] showed that road traffic deaths will increase on average by over $80 \%$ in low-income and middle-income countries in 2020 compared to 1990. As low- and middleincome countries account for $90 \%$ of the world's road deaths, a reduction of $30 \%$ of road deaths in high-income countries is unlikely to result in a net decrease in global road fatalities. According to another prediction of the World Bank [3] South
Asia will witness the largest growth in road traffic deaths between 2000 and 2020, with a dramatic increase of 144\%.

Cambodia is one of these South Asian countries with a current population of approximately 15 million inhabitants. Its population is growing rapidly as does the number of motor vehicles and road traffic deaths. Fatalities grew from 91 in 1995 to 824 in 2003. This problem has been brought to the attention in the first National Road Safety Action Plan (NRSAP) (20062010) of 2004 [4]. In this plan targets were set for the fatality rates in 2010 and in 2020 as agreed between all ASEAN countries (Association of South East Asian Nations). These targets are not more than 7 fatalities per 10,000 vehicles by 2010 and not more than 2 fatalities per 10,000 vehicles by 2020 [5]. The target for 2010 turned out to be far too ambitious (see Table 1).

In 2010, a new road safety target for 2011-2020 was proposed by the road safety stakeholders in Cambodia. In the same period the Organization for Economic Cooperation and 
Development/International Transport Forum (OECD/ITF) had initiated a project that was to provide support for the improvement of the road crash data registration in Cambodia and for the use of these data in developing an effective road safety policy. Many reports of road safety experts and committees have explored the requirements for effectively managing a road safety programme (e.g., OECD/ITF [6] and OECD [7]). Apart from a vision and targets effective implementation of strategies and actions are necessary, supported through a positive political environment and synergies with other related policy areas [6]. So target setting is a necessary but not sufficient condition for effective road safety management. The effects of quantified targets on fatality reductions have been researched several times [8-11]. The overall results suggest that target setting is associated with a substantial positive effect on the trend in road fatalities during the period in which the targets were in effect. The studies included only high-income countries. The interactions among possible influential factors like the presence of detailed road safety programmes, long-term commitments, and expenditures on these programmes were not taken into consideration but may have contributed to the effect [10]. Notably these confounding factors may differ between high- and low-income countries and deserve further exploration. Nevertheless the setting of a quantified target was considered to be a key element and starting point for developing effective road safety management in Cambodia. To prevent setting too ambitious targets, it was decided to underpin the target with a baseline forecast of the fatalities in the target year. In the framework of this project, a road safety forecast for the number of road fatalities in 2011-2020 was also developed.

In this paper, we discuss the methodology used to estimate these forecasts and present the resulting expected number of fatalities as well as the new Cambodian national target that was set for 2020 based on these forecasts.

\section{Background}

The target for 2020 in the previous Cambodian NRSAP (2004) was set at 2 fatalities per 10,000 motor vehicles. Compared to the actual fatality rate of 18.4 per 10,000 motor vehicles in 2003, this implies a reduction of $89 \%$, a very ambitious target; see Table 1 . However, we should consider not only the fatality rate but also the absolute number of fatalities. The future number of fatalities will depend on changes in the use and modes of transportation, in particular the number of motorized vehicles. In Cambodia motorized vehicles are mainly motorbikes. If the number of motorized vehicles would remain at the same level as in 2003 the number of fatalities should also decrease by $89 \%$, that is, from 824 to 91 fatalities, in order to meet the target of 2 fatalities per 10,000 motor vehicles in 2020 . However, considering the continuous increase in the number of vehicles since 2003, the number of vehicles is expected to be much higher in 2020 than in 2003. If this number will be ten times as large as in 2003 (i.e., 4.47 million motorized vehicles), for example, then a target of 2 fatalities per 10,000 motor vehicles would approximately correspond to 895 fatalities in 2020, which is even a modest increase compared to the 814 fatalities in 2003.
TABLE 1: Observed numbers of fatalities (in absolute numbers), observed numbers of motor vehicles (in thousands), and fatality risk (fatalities per thousand vehicles) in Cambodia for the years 19952009.

\begin{tabular}{lccc}
\hline Year & Fatalities & $\begin{array}{c}\text { Motor vehicle } \\
\text { fleet }\end{array}$ & Fatality risk \\
\hline 1995 & 91 & 202.190 & 0.45 \\
1996 & 94 & 228.922 & 0.41 \\
1997 & 83 & 256.330 & 0.32 \\
1998 & 102 & 277.211 & 0.38 \\
1999 & 196 & 304.918 & 0.64 \\
2000 & 401 & 335.069 & 1.20 \\
2001 & 459 & 369.298 & 1.24 \\
2002 & 535 & 420.418 & 1.27 \\
2003 & 824 & 447.428 & 1.84 \\
2004 & 1042 & 485.612 & 2.15 \\
2005 & 904 & 574.829 & 1.57 \\
2006 & 1292 & 714.463 & 1.80 \\
2007 & 1545 & 868.852 & 1.78 \\
2008 & 1638 & 1084.320 & 1.51 \\
2009 & 1717 & 1391.656 & 1.23 \\
\hline
\end{tabular}

${ }^{*}$ Please note that the fatality risk has been expressed in fatalities per ten thousand vehicles.

This example illustrates that it might be easier to understand a target formulated in terms of a reduction in the absolute number of fatalities and also that future changes in motorization should be explicitly taken into account when setting this target. As a result a new road safety target was proposed in terms of a percentage reduction of the baseline forecast for the number of fatalities in 2020, that is, their projected number without additional road safety measures (in other words based on a "business as usual" scenario).

In the past various methods have been developed to obtain forecasts of fatalities in the absence of additional road safety measures [12]. In theory forecasts should involve causal factors that contribute to the incidence of crashes [13]. However, this requires a detailed and quantitative knowledge of these causal factors and that knowledge is still lacking. Even if knowledge about these causal factors would be available, however, they still would all have to be forecasted too in order to predict the future number of fatalities. For this reason, it is common to extrapolate the historical time trend in the number of fatalities.

About one crucial causal factor of the incidence of road crashes, however, data is available for Cambodia. This is the annual number of motorized vehicles which can be considered as a proxy for the exposure to risk in Cambodia. The number of fatalities is often defined as the product of two factors: the number of fatalities divided by the number of motorized vehicles (which is a measure of the fatality risk or rate) and the number of motorized vehicles (which is a measure of the exposure to risk).

Generally, fatality rates can also be based on the size of the population or on the number of kilometres travelled 


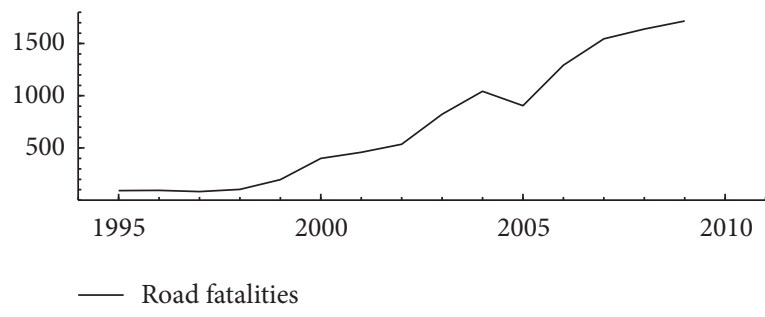

(a)

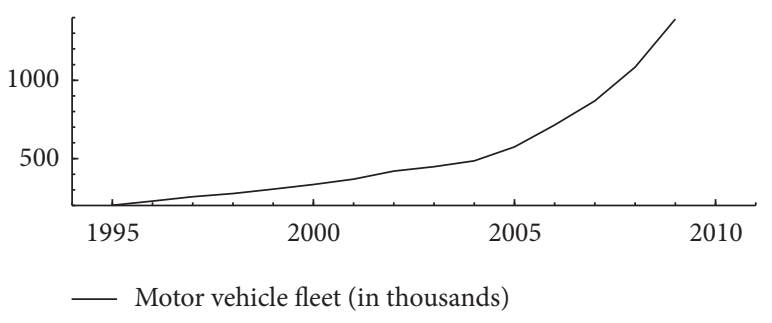

(b)

FIGURE 1: Plots of observed numbers of fatalities (a) and of number of motor vehicles in thousands (b) in Cambodia for the years 1995-2009.

in a country as a denominator. However, the size of the population would not be a good proxy for the exposure to risk in Cambodia since the recent development of the vehicle fleet in Cambodia is probably a better approximation of this exposure. Moreover, the size of the vehicle fleet was also used as denominator for the fatality rate in the previous Cambodia NRSAP of 2004. Travel volume data might have been an even better proxy for exposure but these are not available in Cambodia.

Different types of models have been used for the extrapolation of time trends in fatality rates, ranging from deterministic models such as classic linear regression models (e.g., [14]), log-linear regression models (e.g., [14, 15]), and logistic and exponential models [16] to more advanced stochastic models like ARIMA models (e.g., [17]), the DRAG model [18], and structural time series models (e.g., [19-21]). Deterministic models are not well-equipped to handle the dependencies inherently present in time series observations, while stochastic models are. This is especially important when it comes to the proper use of statistical tests and to the construction of appropriate confidence limits; see Commandeur et al. [22] for details. In order to obtain forecasts of the fatality risk in 2011-2020 in Cambodia it was decided to apply a dedicated structural time series model allowing for the simultaneous analysis of fatalities and motor vehicle data called the latent risk time series model [19].

In some countries forecasts for the number of motor vehicles are based on studies performed by transport researchers. In Cambodia, however, no such studies have been done so far and the expected number of motor vehicles in 2020 was therefore obtained by consulting national experts with the results presented in Section 4.2.

Generally, developments in casualty risks (i.e., rates) tend to be more stable than the separate developments in the number of casualties and in the number of motor vehicles (or other proxies for the exposure in a country) from which the casualty risk is derived (i.e., as the ratio of the two). In combination with good forecasts for the number of motor vehicles or with growth scenarios for the number of motor vehicles this leads to a preference for forecasting risks rather than casualties.

In recent studies the projected time trend is sometimes modified. Using an approach based on extrapolation, one assumes past time trends to continue into the future. Implicitly, it is assumed that future road safety policy will result in a further continuation of past baseline trends. In reality, future trends will differ from those in the past as a result of changes in road safety policy, changes in the effectiveness of policy, and other factors. To a certain extent these changes are known or can be estimated, and therefore the baseline forecast can be "corrected" for these changes. Such an approach was, for example, followed by Broughton and Knowles [15], Corben et al. [23], and Weijermars and Wesemann [12].

However, in Cambodia little quantitative data and knowledge are available on (the effect of) previous and current road safety measures, so it was not possible to correct the future trend.

\section{Methodology}

3.1. Approach and Data. A baseline forecast of the number of fatalities per 1,000 motor vehicles in 2020 was made by extrapolation of the historical trend in the fatality risk. This baseline forecast was made assuming that no additional countermeasures would be implemented in Cambodia "business as usual." Complementary to these latter forecasts, forecasts based on three growth scenarios for the number of motor vehicles in 2020 were provided by consulting local experts. The number of fatalities in 2020 was obtained by multiplication of the outcomes of these two forecasts.

In 2010 fatality data and data on the number of registered motor vehicles (mainly motorbikes) were available for the period 1995-2009; see Table 1 and Figure 1.

The data on fatalities 1995-2009 were obtained from the Road Crash and Victim Information System. These data are collected by the police and also by hospitals. The system was run in 2010 by the Ministry of Interior, Ministry of Health, and Ministry of Public Works and Transport in cooperation with Handicap International. The registration of motor vehicles is performed and maintained by the Ministry of Public Works and Transport. It is hard to assess the quality of these data. As always, one should be prepared for missing and/or incorrect data.

3.2. Forecasting Methodology. The number of fatalities and the best available exposure indicator for Cambodia in Table 1 and Figure 1 were analysed simultaneously with the bivariate latent risk time series model of Bijleveld et al. [19]; see also Durbin and Koopman [24, Section 3.3.3]. For further details of the methodology used in this paper we refer to Appendix A and the just mentioned references. 
In Dupont et al. [21] this model was applied for the forecasting of the annual fatality numbers in 30 European countries. The model is based on the assumption that the amount of exposure and the number of fatalities are intrinsically related. It captures the dynamic evolution in the fatalities as the product of the dynamic evolution in two latent trends: the trend in the fatality risk and the trend in the exposure to that risk. The latter two trends are specified as local linear trends; see Harvey [25], Commandeur and Koopman [26], and Durbin and Koopman [24] for details. Another assumption of the latent risk time series model is that both the registered number of fatalities and the registered number of motor vehicles are contaminated with measurement error (which they almost certainly are).

The optimally modelled trends (see Appendix B for the estimated model parameters) were next projected into the future, thus yielding forecasts and confidence intervals for the fatality risk expressed as a function of the number of fatalities per 1,000 motor vehicles for the years 2010-2020. These are the baseline forecasts, that is, how we would expect the historical risk trend to evolve according to a "business as usual" scenario. The forecasted values of fatality risk for the years $2010-2020$ were then multiplied by the expected number of motor vehicles in this same period to obtain the estimated number of fatalities. The expectations of the growth in the number of motor vehicles were based on estimates provided by national experts. In some countries the quantified effects of single road safety measures are known from previous studies; this allows one to estimate the effect of the introduction of a single new safety measure or even of a complete road safety programme consisting of several new road safety measures simultaneously. It thus becomes possible to adapt the baseline forecast for the expected effect of new safety measures or to perform an ex-ante evaluation as presented in Siegrist [27] and applied in Weijermars and Wesemann [12]. However, in Cambodia, it was not feasible to make such adaptations to the baseline forecast because the relevant data are unavailable.

\section{Results}

4.1. Fatality Risk. The latent risk time series model yielded forecasts for the number of fatalities per 1,000 motor vehicles (the fatality risks) that are given in Table 2 , including their $68 \%$ confidence limits.

4.2. Motor Vehicles. When invited to estimate the growth of the number of motor vehicles in Cambodia for the years 2010-2020, national experts foresaw the three possible scenarios shown in Table 3. The first growth scenario for the number of motor vehicles in 2020 is a low estimate of 1,391,656 in 2009 (see Table 1) plus 3 million vehicles, the second is a middle estimate of 1,391,656 in 2009 plus 4 million vehicles, and the third is a high estimate of 1,391,656 in 2009 plus 5 million vehicles.

4.3. Fatalities. The forecasted values of the fatality risk for the years 2010-2020 in Table 2 were multiplied by the expected
TABLE 2: Forecasted absolute values of Cambodian fatality risk (i.e., number of fatalities per thousand motor vehicles) in the years 2010 2020 , including their $68 \%$ confidence limits.

\begin{tabular}{cccc}
\hline Year & Absolute risk & Lower bound & Upper bound \\
\hline 2010 & 1.04391 & 0.79097 & 1.297159 \\
2011 & 0.89868 & 0.55649 & 1.242678 \\
2012 & 0.79288 & 0.38683 & 1.204927 \\
2013 & 0.71937 & 0.26398 & 1.190057 \\
2014 & 0.67079 & 0.17675 & 1.197959 \\
2015 & 0.64034 & 0.11619 & 1.228209 \\
2016 & 0.62219 & 0.07507 & 1.281228 \\
2017 & 0.61155 & 0.04772 & 1.358552 \\
2018 & 0.60472 & 0.02987 & 1.462963 \\
2019 & 0.59896 & 0.01842 & 1.598648 \\
2020 & 0.59237 & 0.01120 & 1.771461 \\
\hline
\end{tabular}

TABle 3: Possible scenarios (low, middle, and high) for future motor vehicle ownership (in thousands) in Cambodia for the years 20102020.

\begin{tabular}{cccc}
\hline Year & Low & Middle & High \\
\hline 2010 & 1664.383 & 1755.292 & 1846.201 \\
2011 & 1937.111 & 2118.929 & 2300.747 \\
2012 & 2209.838 & 2482.565 & 2755.292 \\
2013 & 2482.565 & 2846.201 & 3209.838 \\
2014 & 2755.292 & 3209.838 & 3664.383 \\
2015 & 3028.020 & 3573.474 & 4118.929 \\
2016 & 3300.747 & 3937.111 & 4573.474 \\
2017 & 3573.474 & 4300.747 & 5028.020 \\
2018 & 3846.201 & 4664.383 & 5482.565 \\
2019 & 4118.929 & 5028.020 & 5937.111 \\
2020 & 4391.656 & 5391.656 & 6391.656 \\
\hline
\end{tabular}

number of motor vehicles in this same period in Table 3 in order to obtain the expected number of fatalities. This was done for each of the three vehicle growth scenarios. For example, the expected number of fatalities in 2020 for the low vehicle growth scenario is $(0.59237)(4391.656)=$ 2,602 (with a lower bound of $(0.01120)(4391.656)=49$ fatalities and an upper bound of $(1.771461)(4391.656)=7,780$ fatalities); for the middle and high vehicle growth scenarios it is $(0.59237)(5391.656)=3,193$ and $(0.59237)(6391.656)=$ 3,786 , respectively. The complete results of the fatality forecasts for the years 2010-2020 according to the three vehicle growth scenarios are given in Tables 4, 5, and 6 and plotted in Figures 2, 3, and 4, respectively.

It may be noted that the uncertainty, as indicated by the confidence limits, surrounding the forecasts in Figures 2, 3, and 4 becomes larger and larger as the forecasts are for time points further and further into the future. This is as one would expect on intuitive grounds. 
TABLE 4: Forecasted absolute numbers of Cambodian fatalities in the years 2010-2020, including their $68 \%$ confidence limits, according to the low vehicle growth scenario.

\begin{tabular}{lccc}
\hline Year & Lower bound & Fatalities & Upper bound \\
\hline 2010 & 1316.5 & 1737.5 & 2159.0 \\
2011 & 1078.0 & 1740.8 & 2407.2 \\
2012 & 854.8 & 1752.1 & 2662.7 \\
2013 & 655.3 & 1785.9 & 2954.4 \\
2014 & 487.0 & 1848.2 & 3300.7 \\
2015 & 352.0 & 1939.0 & 3719.0 \\
2016 & 248.0 & 2054.0 & 4229.0 \\
2017 & 171.0 & 2185.4 & 4854.8 \\
2018 & 115.0 & 2325.9 & 5626.9 \\
2019 & 76.0 & 2467.1 & 6584.7 \\
2020 & 49.2 & 2601.5 & 7779.6 \\
\hline
\end{tabular}

TABLE 5: Forecasted absolute numbers of Cambodian fatalities in the years $2010-2020$, including their $68 \%$ confidence limits, according to the middle vehicle growth scenario.

\begin{tabular}{lccc}
\hline Year & Lower bound & Fatalities & Upper bound \\
\hline 2010 & 1388.4 & 1832.4 & 2276.9 \\
2011 & 1179.2 & 1904.2 & 2633.1 \\
2012 & 960.3 & 1968.4 & 2991.3 \\
2013 & 751.3 & 2047.5 & 3387.1 \\
2014 & 567.3 & 2153.1 & 3845.3 \\
2015 & 415.2 & 2288.2 & 4389.0 \\
2016 & 295.6 & 2449.6 & 5044.3 \\
2017 & 205.2 & 2630.1 & 5842.8 \\
2018 & 139.3 & 2820.6 & 6823.8 \\
2019 & 92.6 & 3011.6 & 8038.0 \\
2020 & 60.4 & 3193.9 & 9551.1 \\
\hline
\end{tabular}

TABLE 6: Forecasted absolute numbers of Cambodian fatalities in the years $2010-2020$, including their $68 \%$ confidence limits, according to the high vehicle growth scenario.

\begin{tabular}{lccc}
\hline Year & Lower bound & Fatalities & Upper bound \\
\hline 2010 & 1460.3 & 1927.3 & 2394.8 \\
2011 & 1280.3 & 2067.6 & 2859.1 \\
2012 & 1065.9 & 2184.6 & 3319.9 \\
2013 & 847.3 & 2309.1 & 3819.9 \\
2014 & 647.7 & 2458.0 & 4389.8 \\
2015 & 478.6 & 2637.5 & 5058.9 \\
2016 & 343.4 & 2845.6 & 5859.7 \\
2017 & 239.9 & 3074.9 & 6830.8 \\
2018 & 163.8 & 3315.4 & 8020.8 \\
2019 & 109.4 & 3556.1 & 9491.3 \\
2020 & 71.6 & 3786.2 & 11322.8 \\
\hline
\end{tabular}

\section{Target Setting}

During the preparations of the target setting for 2011-2020 it was decided to use the middle vehicle growth scenario in Table 5 and Figure 3 as a starting point and to consider

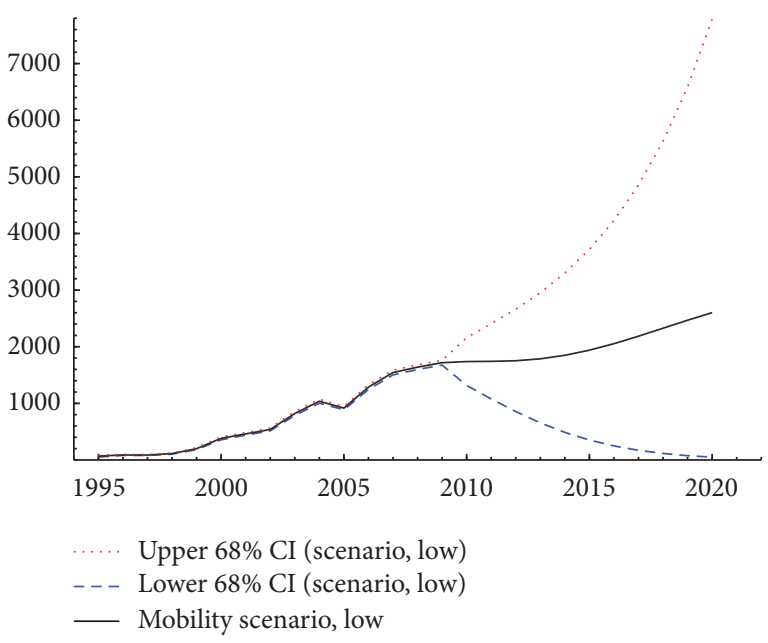

FIGURE 2: Modelled (1995-2009) and forecasted (2010-2020) absolute numbers of Cambodian fatalities, including their $68 \%$ confidence limits, according to the low vehicle growth scenario.

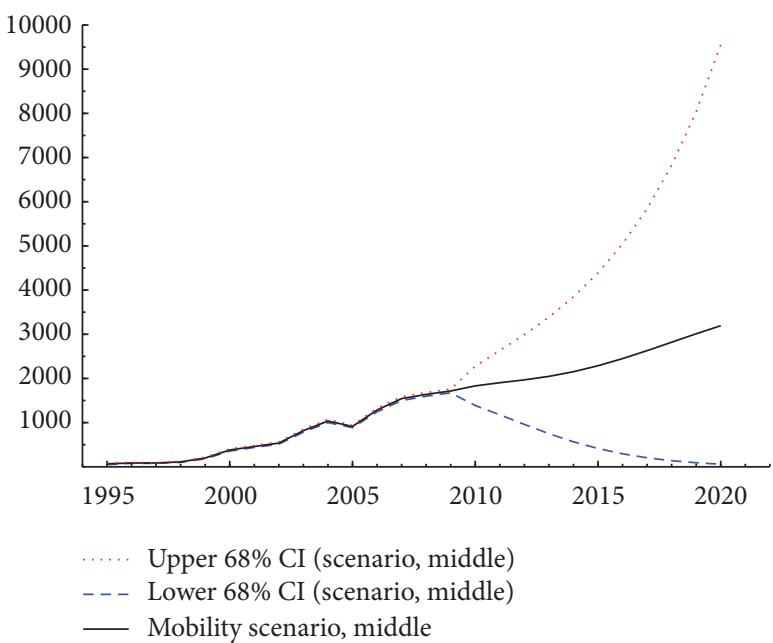

FIGURE 3: Modelled (1995-2009) and forecasted (2010-2020) absolute numbers of Cambodian fatalities, including their $68 \%$ confidence limits, according to the middle vehicle growth scenario.

the corresponding forecasts as the number of fatalities to be expected if no additional efforts would be made to improve road safety in Cambodia.

The baseline forecast of the number of fatalities without additional actions was thus estimated to be 3,194 or 3,200 fatalities (rounded) in 2020. The new target was set to reduce this number by taking additional actions with $50 \%$ to 1,600 fatalities; this decision was made in a "top down" way mainly based on political arguments and because a "bottom up" approach (i.e., based on an ex-ante evaluation of new policy) was not feasible. This reduction of $50 \%$ is some 200 fatalities less than the 1,816 fatalities observed in 2010 which was the year of setting the target in 2020. So in the systematics of the Decade of Action one would speak of a target of minus $11 \%$, being the fatality reduction in 2020 compared with the reference year 2010. For each of the 10 years up to and 
TABLE 7: The estimated number of fatalities in Cambodia with and without additional actions in 2011-2020.

\begin{tabular}{|c|c|c|c|c|c|c|c|c|c|c|}
\hline & 2011 & 2012 & 2013 & 2014 & 2015 & 2016 & 2017 & 2018 & 2019 & 2020 \\
\hline Number of fatalities: without additional actions & 1904 & 1968 & 2048 & 2153 & 2288 & 2450 & 2630 & 2821 & 3012 & 3194 \\
\hline Number of fatalities: with additional actions & 1809 & 1772 & 1740 & 1722 & 1716 & 1715 & 1710 & 1692 & 1656 & 1597 \\
\hline Percentage reduction & $5 \%$ & $10 \%$ & $15 \%$ & $20 \%$ & $25 \%$ & $30 \%$ & $35 \%$ & $40 \%$ & $45 \%$ & $50 \%$ \\
\hline Absolute reduction & 95 & 197 & 308 & 431 & 572 & 735 & 921 & 1128 & 1355 & 1597 \\
\hline Total & \multicolumn{10}{|c|}{7350} \\
\hline
\end{tabular}

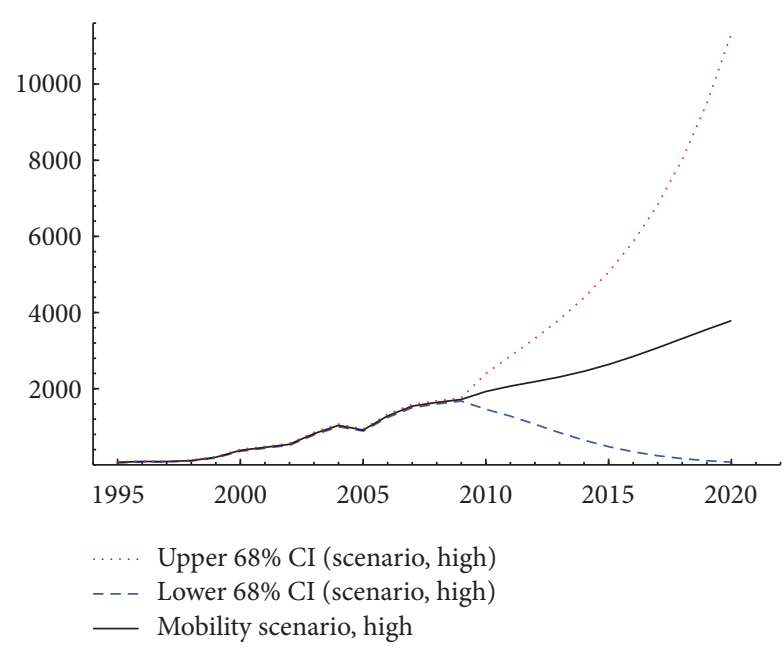

Figure 4: Modelled (1995-2009) and forecasted (2010-2020) absolute numbers of Cambodian fatalities, including their $68 \%$ confidence limits, according to the high vehicle growth scenario.

including 2020 an interim objective was set of an additional reduction of approximately $5 \%$ per year, ending up with a $50 \%$ reduction in 2020 . If the additional actions turn out to be effective, over the whole period of 2011-2020, a total of 7,350 fatalities will be saved in comparison with the baseline forecast of 3,200 fatalities for 2020, as indicated in Figure 5 and Table 7.

\section{Discussion and Conclusions}

We have shown how forecasts for the expected number of road traffic fatalities in 2020 were obtained for the National Road Safety Target 2011-2020; we did the most with data and knowledge available in Cambodia, including a quantification of the large uncertainty surrounding these forecasts. As a proxy for the exposure to risk the registered annual number of motor vehicles in 1995-2009 was used, while their forecasts were based on three possible growth scenarios provided by local experts. Applying the latent risk time series model to the simultaneous analysis of the annual number of fatalities and the annual number of motor vehicles in 1995-2009 resulted in forecasts of the fatality risk for the years 2010-2020. Estimates for the expected number of fatalities in the years 20102020, including their confidence limits, were obtained by

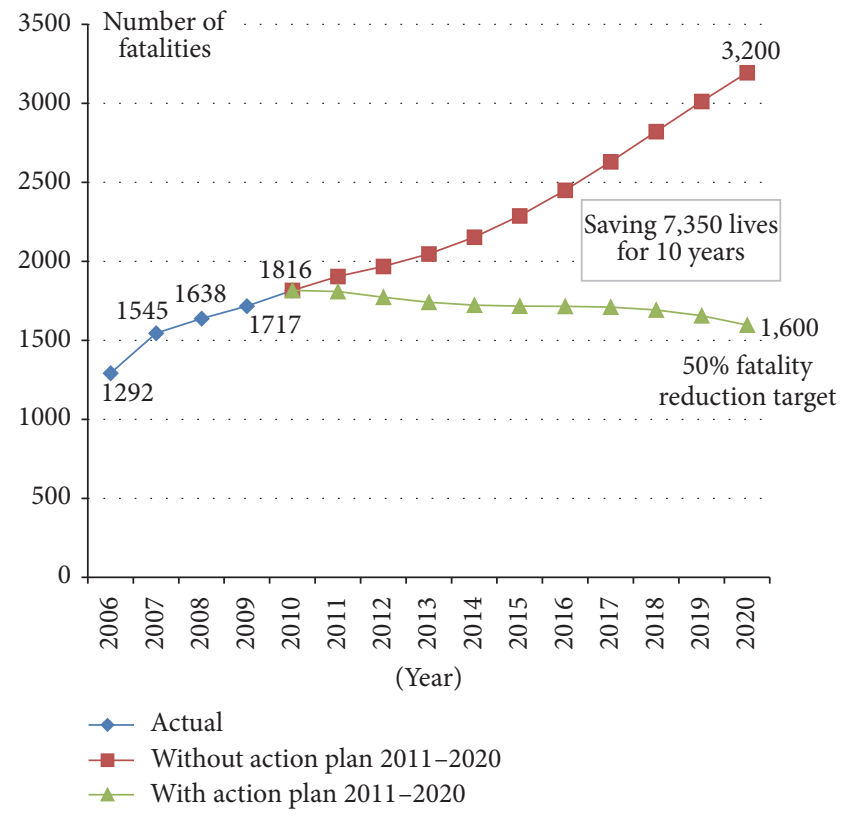

Figure 5: Potential of the National Road Safety Action Plan 20112020.

multiplying these forecasts of the fatality risk by the three growth scenarios for the number of motor vehicles.

It was decided to use the forecasts corresponding to the middle growth scenario as the baseline forecast for what to expect in 2020 without any additional efforts: approximately 3,200 fatalities. This forecast is embedded in various uncertainties: the data quality, the lack of data concerning past and future road safety measures, and hence the assumptions that had to be made on transport and traffic safety policy (business as usual). Still from the viewpoint of decision makers the forecast reduced the uncertainties that they were facing anyhow when preparing a target for 2020. Based on our experiences in Cambodia, we suggest that other low-income countries in the South East Asian region would benefit as well from this type of fatality forecasting. Sound data on fatalities and travelling or vehicle fleet are a prerequisite. It was further decided in a "top down" way to set the target in 2020 at $50 \%$ of this number or 1,600 fatalities. If, moreover, this $50 \%$ reduction due to additional efforts is achieved by a reduction of approximately 5\% every year, then it is expected that a total of 3,750 lives could be saved in the whole period of 2011-2020. It may be noted that this annual reduction of 
approximately $5 \%$ is somewhat higher than the ambition level of $4.5 \%$ reduction discussed in Sze et al. [28] who found a lower likelihood of target success for ambition levels set higher than $4.5 \%$ in more developed countries.

It is intended to monitor annually the implementation and effects of the new NRSAP, 2011-2020; the intermediate annual outcomes can be used to expand the efforts of the programme or for adjustments of the target. This information is also valuable to explore the impact on fatalities, not only of target setting but also of confounding factors like the presence of detailed road safety programmes, long-term commitments, and expenditures on these programmes. Previous studies into the effects of quantified target setting included only high-income countries and notably these confounding factors may differ between high- and low-income countries like Cambodia.

\section{Appendix}

\section{A. The Latent Risk Time Series Model}

The methodology used in this paper is based on the state space methodology discussed in Durbin and Koopman [24], Commandeur and Koopman [26], and Bijleveld et al. [19]. The methodology discussed in the just mentioned references is well able to handle the dependencies usually observed in time series data and can easily be extended to the analysis of multivariate time series data.
The general multivariate time series model can be represented in state space form as follows:

$$
\begin{aligned}
& y_{t}=Z_{t} \alpha_{t}+\varepsilon_{t}, \\
& \alpha_{t}=T_{t} \alpha_{t}+R_{t} \eta_{t},
\end{aligned}
$$

for $t=1, \ldots, n$. The observation or measurement (A.1) is for $p \times 1$ vector $y_{t}$ containing the values of $p$ observed time series at time point $t . p \times 1$ irregular vector $\varepsilon_{t}$ contains $p$ observation disturbances, with one for each time series in $y_{t}$. $p$ observation disturbances are assumed to have zero means and an unknown variance-covariance structure represented by variance matrix $H_{t}$ of order $p \times p . m \times 1$ state vector $\alpha_{t}$ contains unobserved variables and unknown fixed effects. Matrix $Z_{t}$ of order $p \times m$ links the unobservable factors and regression effects of the state vector with the observation vector. Matrix $T_{t}$ in (A.2) is called the transition matrix, and is of order $m \times m$. The $r \times 1$ vector $\eta_{t}$ contains the state disturbances. The state disturbances have zero means and unknown variances and covariances, which are collected in the covariance matrix $Q_{t}$ of order $r \times r$. In many standard cases, $r=m$ and matrix $R_{t}$ is identity matrix $I_{m}$. In other cases, matrix $R_{t}$ is $m \times r$ selection matrix with $r<$ $m$. Although matrix $R_{t}$ can be specified freely, it is often composed of a selection from the $r$ columns of the identity matrix $I_{m}$.

By defining

$$
\begin{aligned}
& \alpha_{t}=\left(\begin{array}{c}
\mu_{t}^{(1)} \\
\mu_{t}^{(2)} \\
v_{t}^{(1)} \\
v_{t}^{(2)}
\end{array}\right) \text {, } \\
& \eta_{t}=\left(\begin{array}{c}
\xi_{t}^{(1)} \\
\xi_{t}^{(2)} \\
\zeta_{t}^{(1)} \\
\zeta_{t}^{(2)}
\end{array}\right), \\
& T_{t}=\left(\begin{array}{llll}
1 & 0 & 1 & 0 \\
0 & 1 & 0 & 1 \\
0 & 0 & 1 & 0 \\
0 & 0 & 0 & 1
\end{array}\right), \\
& R_{t}=\left(\begin{array}{llll}
1 & 0 & 0 & 0 \\
0 & 1 & 0 & 0 \\
0 & 0 & 1 & 0 \\
0 & 0 & 0 & 1
\end{array}\right), \\
& Z_{t}=\left(\begin{array}{llll}
1 & 0 & 0 & 0 \\
1 & 1 & 0 & 0
\end{array}\right) \text {, } \\
& H_{t}=\left(\begin{array}{cc}
\sigma_{\varepsilon^{(1)}}^{2} & \operatorname{cov}\left(\varepsilon^{(1)}, \varepsilon^{(2)}\right) \\
\operatorname{cov}\left(\varepsilon^{(1)}, \varepsilon^{(2)}\right) & \sigma_{\varepsilon^{(2)}}^{2}
\end{array}\right) \text {, }
\end{aligned}
$$




$$
Q_{t}=\left(\begin{array}{cccc}
\sigma_{\xi^{(1)}}^{2} & \operatorname{cov}\left(\xi^{(1)}, \xi^{(2)}\right) & 0 & 0 \\
\operatorname{cov}\left(\xi^{(1)}, \xi^{(2)}\right) & \sigma_{\xi^{(2)}}^{2} & 0 & 0 \\
0 & 0 & \sigma_{\zeta^{(1)}}^{2} & \operatorname{cov}\left(\zeta^{(1)}, \zeta^{(2)}\right) \\
0 & 0 & \operatorname{cov}\left(\zeta^{(1)}, \zeta^{(2)}\right) & \sigma_{\zeta^{(2)}}^{2}
\end{array}\right)
$$

we obtain the latent risk time series model consisting of the two observation equations,

$$
\begin{aligned}
& y_{t}^{(1)}=\mu_{t}^{(1)}+\varepsilon_{t}^{(1)}, \\
& y_{t}^{(2)}=\mu_{t}^{(1)}+\mu_{t}^{(2)}+\varepsilon_{t}^{(2)},
\end{aligned}
$$

and the following four state equations:

$$
\begin{aligned}
& \mu_{t+1}^{(1)}=\mu_{t}^{(1)}+v_{t}^{(1)}+\xi_{t}^{(1)}, \\
& \mu_{t+1}^{(2)}=\mu_{t}^{(2)}+v_{t}^{(2)}+\xi_{t}^{(2)},
\end{aligned}
$$

$$
\begin{aligned}
& v_{t+1}^{(1)}=v_{t}^{(1)}+\zeta_{t}^{(1)} \\
& v_{t+1}^{(2)}=v_{t}^{(2)}+\zeta_{t}^{(2)}
\end{aligned}
$$

\section{B. Parameter Estimates}

The maximum likelihood estimates of the variances and covariances obtained with the latent risk model applied to the logarithm of the annual number of motorized vehicles in Cambodia and the logarithm of the annual number of fatalities are

$$
\begin{aligned}
H_{t} & =\left(\begin{array}{ccc}
1.6037 \times 10^{-20} & -8.43623 \times 10^{-21} \\
-8.43623 \times 10^{-21} & 2.77809 \times 10^{-20}
\end{array}\right), \\
Q_{t} & =\left(\begin{array}{cccc}
1.37917 \times 10^{-6} & -2.52119 \times 10^{-4} & 0 & 0 \\
-2.52119 \times 10^{-4} & 1.60488 \times 10^{-3} & 0 & 0 \\
0 & 0 & 4.60885 \times 10^{-2} & -4.16301 \times 10^{-3} \\
0 & 0 & -4.16301 \times 10^{-3} & 1.07987 \times 10^{-2}
\end{array}\right) .
\end{aligned}
$$

\section{Competing Interests}

The authors declare that they have no competing interests.

\section{References}

[1] WHO, Global Status Report on Road Safety 2013, World Health Organization (WHO), Geneva, Switzerland, 2013.

[2] WHO, World Report on Road Traffic Injury Prevention, World Health Organization (WHO), Geneva, Switzerland, 2004.

[3] E. Kopits and M. Cropper, "Traffic fatalities and economic growth," Policy Research Working Paper, World Bank, Washington, DC, USA, 2003.

[4] Royal Government of Cambodia/ National Road Safety Committee, Four-Year Report 2006-2009. Prepared for the First Global Ministerial Conference on Road Safety, Federation, Moscow, Russian, 2009.

[5] Ung Chun Hour, Country Report on Road Safety in Cambodia, Royal Government of Cambodia, Ministry of Public Works and Transport, Phnom Penh, Cambodia, 2007.

[6] OECD/ITF, Towards Zero: Ambitious Road Safety Targets and the Safe System Approach, OECD, Paris, France, 2008.
[7] OECD, Safety on Roads: What's the Vision? OECD, Paris, France, 2002.

[8] R. Elvik, "Quantified road safety targets. An assessment of evaluation methodology," Tech. Rep. 539, Institute of Transport Economics, Oslo, Norway, 2001.

[9] S. C. Wong, N. N. Sze, H. F. Yip, B. P. Y. Loo, W. T. Hung, and H. K. Lo, "Association between setting quantified road safety targets and road fatality reduction," Accident Analysis and Prevention, vol. 38, no. 5, pp. 997-1005, 2006.

[10] S. C. Wong and N. N. Sze, "Is the effect of quantified road safety targets sustainable?" Safety Science, vol. 48, no. 9, pp. 1182-1188, 2010.

[11] R. E. Allsop, N. N. Sze, and S. C. Wong, "An update on the association between setting quantified road safety targets and road fatality reduction," Accident Analysis and Prevention, vol. 43, no. 3, pp. 1279-1283, 2011.

[12] W. Weijermars and P. Wesemann, "Road safety forecasting and ex-ante evaluation of policy in the Netherlands," Transportation Research Part A: Policy and Practice, vol. 52, pp. 64-72, 2013.

[13] E. Hauer, "On prediction in road safety," Safety Science, vol. 48, no. 9, pp. 1111-1122, 2010.

[14] P. Wittenberg, K. Sever, S. Knoth, N. Sahin, and J. Bondarenko, "Determining quantitative road safety targets by applying 
statistical prediction techniques and a multi-stage adjustment procedure," Accident Analysis and Prevention, vol. 50, pp. 566$577,2013$.

[15] J. Broughton and J. Knowles, "Providing the numerical context for British casualty reduction targets," Safety Science, vol. 48, no. 9, pp. 1134-1141, 2010.

[16] S. Oppe, "Macroscopic models for traffic and traffic safety," Accident Analysis and Prevention, vol. 21, no. 3, pp. 225-232, 1989.

[17] F. Van den Bossche, G. Wets, and T. Brijs, "A regression model with ARIMA errors to investigate the frequency and severity of road traffic accidents," Tech. Rep. RA-2004-35, Steunpunt Verkeersveiligheid, Diepenbeek, Belgium, 2004.

[18] P. Fournier and R. Simard, "The DRAG-2 model for Quebec," in Structural Road Accident Models; The International DRAG Family, M. Gaudry and S. Lassarre, Eds., pp. 37-66, Pergamon, 2002.

[19] F. D. Bijleveld, J. J. F. Commandeur, P. Gould, and S. J. Koopman, "Model-based measurement of latent risk in time series with applications," Journal of the Royal Statistical Society A, vol. 171, no. 1, pp. 265-277, 2008.

[20] C. Antoniou and G. Yannis, "State-space based analysis and forecasting of macroscopic road safety trends in Greece," in Proceedings of the Transport Research Arena (TRA '12), P. Papaioannou, Ed., Athens, Greece, April 2012, Procedia-Social and Behavioral Sciences, vol. 48, pp. 1589-1598, 2012 .

[21] E. Dupont, J. J. F. Commandeur, S. Lassarre et al., "Latent risk and trend models for the evolution of annual fatality numbers in 30 European countries," Accident Analysis and Prevention, vol. 71, pp. 327-336, 2014.

[22] J. J. F. Commandeur, F. D. Bijleveld, R. Bergel-Hayat, C. Antoniou, G. Yannis, and E. Papadimitriou, "On statistical inference in time series analysis of the evolution of road safety," Accident Analysis and Prevention, vol. 60, pp. 424-434, 2013.

[23] B. F. Corben, D. B. Logan, L. Fanciulli, R. Farley, and I. Cameron, "Strengthening road safety strategy development 'Towards Zero' 2008-2020-Western Australia's experience schientific research on road safety management SWOV workshop 16 and 17 November 2009," Safety Science, vol. 48, no. 9, pp. 10851097, 2010.

[24] J. Durbin and S. J. Koopman, Time Series Analysis by State Space Methods, Oxford University Press, 2nd edition, 2012.

[25] A. C. Harvey, Forecasting, Structural Time Series Models and the Kalman Filter, Cambridge University Press, Cambridge, UK, 1989.

[26] J. J. Commandeur and S. J. Koopman, An Introduction to State Space Time Series Analysis, Practical Econometrics, Oxford University Press, Oxford, UK, 2007.

[27] S. Siegrist, "Towards a method to forecast the effectiveness of national road safety programmes," Safety Science, vol. 48, no. 9, pp. 1106-1110, 2010.

[28] N. N. Sze, S. C. Wong, and C. Y. Lee, "The likelihood of achieving quantified road safety targets: a binary logistic regression model for possible factors," Accident Analysis and Prevention, vol. 73, pp. 242-251, 2014. 


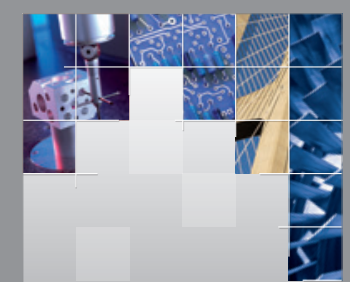

\section{Enfincering}
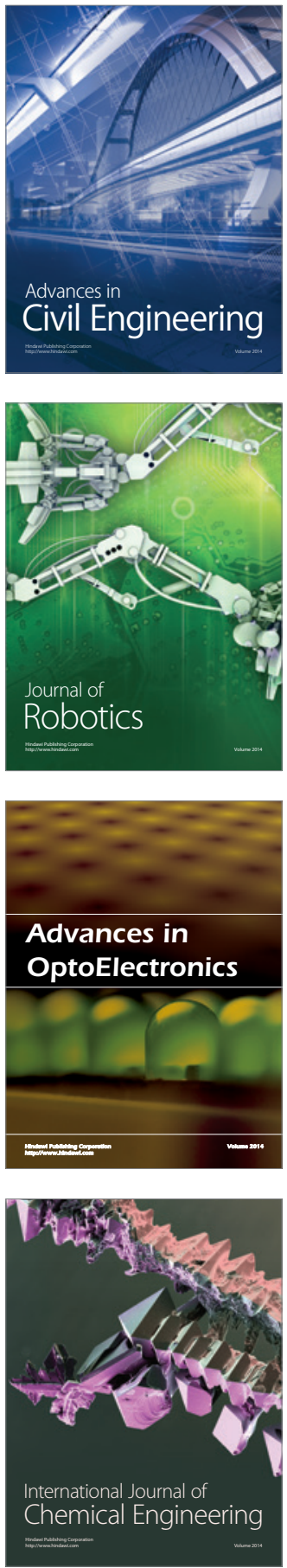

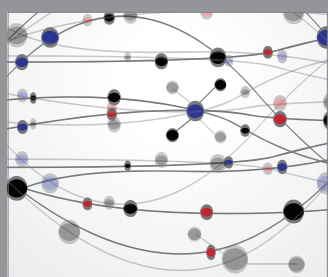

The Scientific World Journal

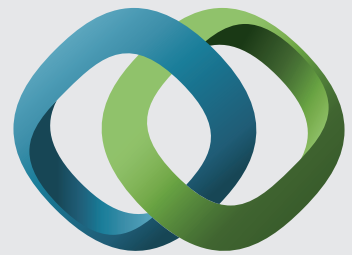

\section{Hindawi}

Submit your manuscripts at

https://www.hindawi.com
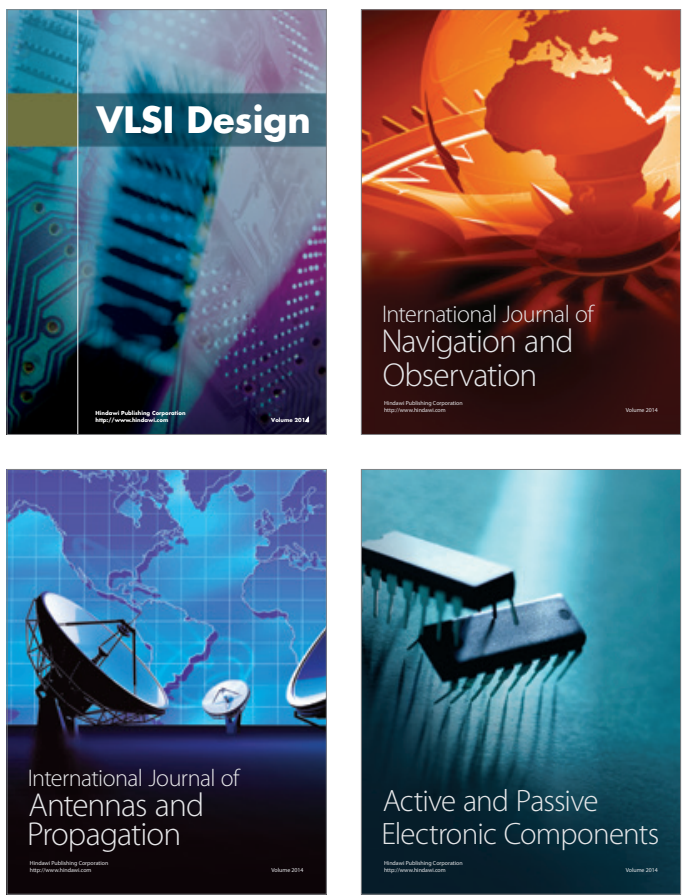
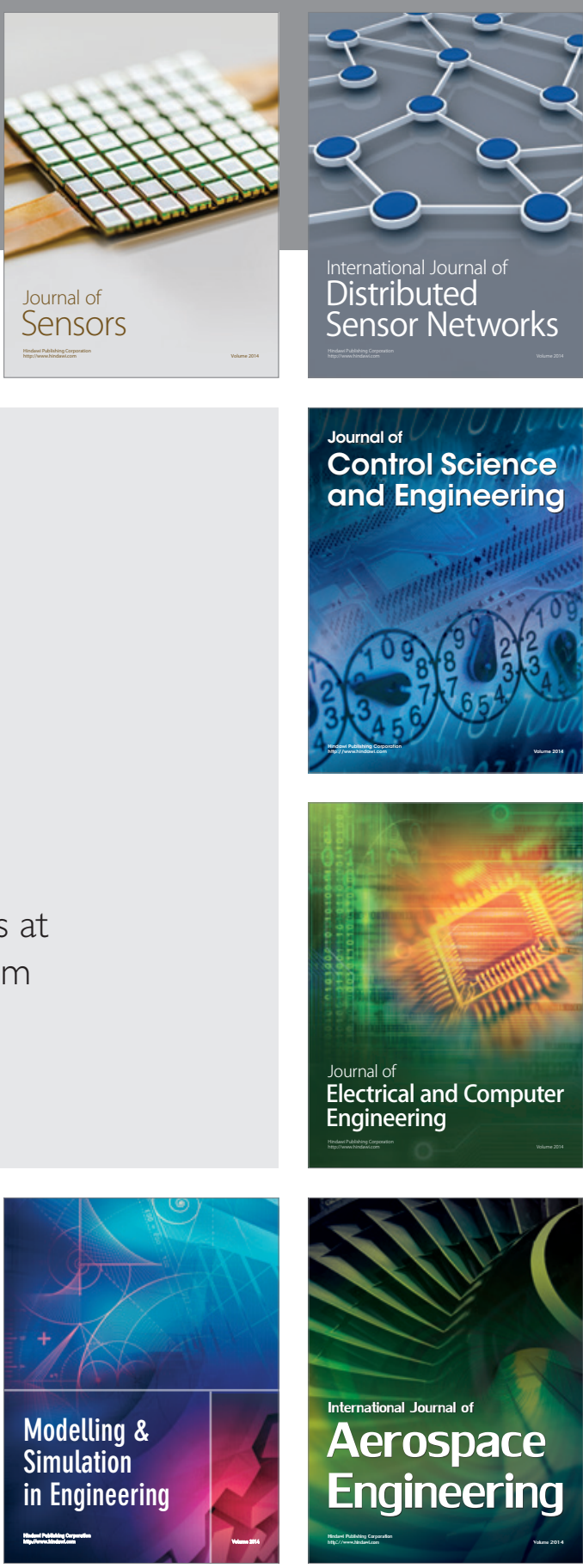

International Journal of

Distributed

Sensor Networks

$-$

Joumal of

Control Science

and Engineering
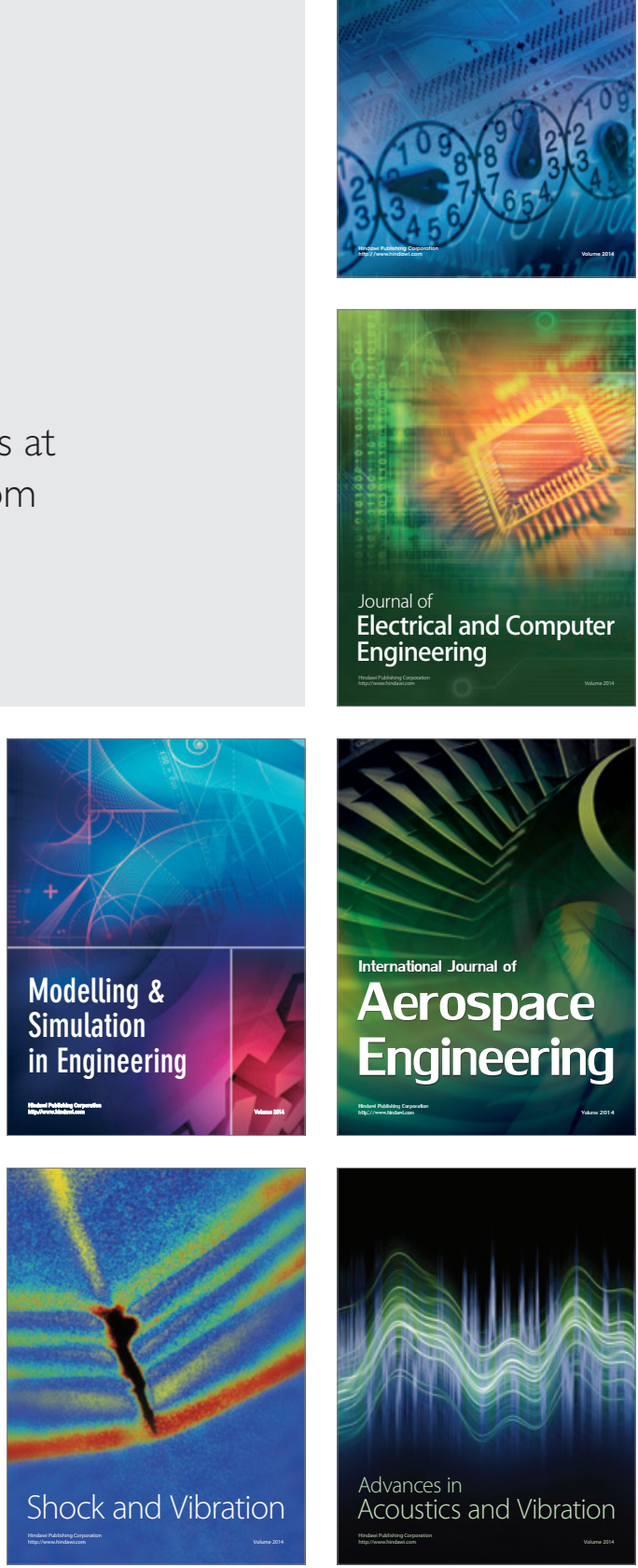